\title{
Modeling of reliability of power supply systems with autonomous energy source
}

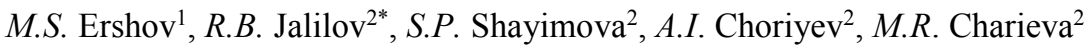 \\ ${ }^{1}$ Russian State University of Oil and Gas (National Research University) named after I.M. Gubkin, Moscow, Russia \\ ${ }^{2}$ Bukhara Engineering-Technological Institute
}

\begin{abstract}
The methodology for calculating the reliability of power supply systems with autonomous and mixed energy sources has been considered. Autonomous sources are widely used in industrial power supply systems as primary, backup or emergency sources. The functioning and interchangeability of these systems has features that affect the reliability of power supply. The proposed methodology is based on the method of semi-Markov random processes and can be used for comparative analysis of the reliability of options for power supply systems. The methodology has been brought to software implementation and is accompanied by an example of calculating the reliability of the power supply system for stationary marine oil production platforms.
\end{abstract}

\section{Introduction}

Objects of production, transportation and refining of oil and gas are complex continuous production, which put increased requirements for the reliability of power supply [1-4]. Autonomous power plants of own needs (PPPON) based on diesel or gas turbine units are used to power consumers of electricity in oil and gas industries. Depending on the number and type of PPPON units used, the conditions for their parallel operation with centralized power supply sources, various options for power supply systems with autonomous power supplies can be used. For a comparative analysis of the reliability of options for power supply systems, a technology based on the mathematical method of semi-Markov random processes is proposed [5-8].

\section{The methodology for modeling and calculating the reliability of power supply system}

Includes the following steps $[2,6,7]$ :

- Formation of the space and graph of the state of the system;

- Mathematical description of the space and graph of the state of the system;

- Determination of indicators of system reliability.

Formation of the space and graph of the state of the system.

When performing this stage, for power supply systems it is necessary to take into account the working, standby and repair conditions of power supplies and system connections, i.e. power lines, connecting distribution devices of 6 (10) $\mathrm{kV}$ technological installations to which generators of autonomous power sources are connected. Along with structural redundancy, characterized by a reserve of generating capacities and backup links, power supply systems also have a temporary reserve $[4,7,10]$. Temporary redundancy consists in the fact that consumers allow a short interruption in power supply. A break in the power supply during the operation of the automatic switch-on reserve (ASOR) does not stop the process and not considered as failure. Along with failures of elements (sources, lines) and failures in the operation of the reserve input, it is necessary to take into account the possibility of system failures, which may be due to interruptions in the supply of fuel to generating electrical units and the failure of relay protection of power supply systems

Failures of system elements occur with the intensity $\lambda_{i}, 1 /$ year; and recovery occurs with the intensity $\mu_{i}, 1 /$ year; $(i=1, \ldots n) . . n$ is the number of the main elements (sources and lines) of the system. Failure and restoration intensity of elements are inverse to their average time between failures and average times of recovery, respectively.

The possibility of an unsuccessful ABP is characterized by probability $q_{\mathrm{ABP}}$. The probability of a successful ABP is characterized by probability $\left(1-q_{\mathrm{ABP}}\right)$. The probabilities of events make it possible to "sift" the flow of failures and recoveries [9, 11]. In case of unsuccessful ABP, the operator carries

\footnotetext{
* Corresponding author: zhalilov.rashid@mail.ru
} 
out the input of the generating unit or the turning on of system communication manually. Manual entry of the power plant unit into operation is carried out with intensity $\mu_{\text {ap }}$.Manual connection of communication or sectional switch is carried out with intensity $\mu_{\mathrm{cp}}$.

System failures are characterized by the intensity of complete $\lambda_{S}$ or the intensity of partial $\lambda_{S S}$ failures and recoveries $\boldsymbol{\mu}_{S}$ or $\boldsymbol{\mu}_{S S}$, respectively. The rates of system failures associated with the probability $q_{\mathrm{P} 3}$ of failure of the protection are determined by the product of the rate of accidents in the network of the system $\lambda_{C}$ and the specified probability.

The state and transition graph is formed based on the analysis of possible states and includes a finite set of states $\mathbf{X}=\left\{x_{1}, x_{2}, x_{3}, \ldots x_{n}\right\}$, which is divided into subsets of functional $\mathbf{X}_{\text {PC }}$ and non-functional $\mathbf{X}_{\text {HPC }}$ states. In the formation of states, it is necessary to take into account the main states and neglect the secondary ones. It is accepted that the combination of independent failures of more than three main elements of the system is impossible [3, 5]. A subset of nonfunctional states can be divided into a number of levels, ranked by the energy deficit in the system.

\section{Mathematical description of the space and graph of state of the system.}

Initially, the process is described by the matrix $\left\{\lambda_{i j}\right\}$ of intensities of transitions of the system from one state to another. Based on the intensity matrix, the vector $\left\{a_{i}\right\}$ of the average residence time of the system in states and the matrix $\left\{p_{i j}\right\}$ of transition probabilities between states are determined. The element $\boldsymbol{a}_{i}$ of the vector of the average residence time in the states is defined as the reciprocal of the sum of the intensities of the transitions leaving this state. The element of the transition probability matrix is defined as the ratio of the intensity of the transition from state $x_{i}$ to state $x_{j}$ to the sum of the intensities of all transitions out the state $x_{i}$.

Based on the original matrix $\left\{p_{i j}\right\}$, the vector $\left\{\pi_{i}\right\}$ of stationary probabilities of the process is defined.

Stationary probabilities $\pi_{i}$ are defined from the system of equations [1]

$$
\pi_{i}=\sum_{i, j}^{n} p_{i j} \pi_{j}
$$

and normalization conditions

$$
\sum_{i=1}^{n} \pi_{i}=1
$$

The Gauss method is used to solve the system of equations.

\section{Determination of system reliability indicators}

Calculation of the reliability of power supply to consumers comes to the determination of reliability indicators. A set of reliability indicators includes:

$T_{\mathrm{H}}$, year - average operating time for failures;

$T_{\mathrm{B}}$, hour - average recovery time;

$K_{\Gamma}$ - availability coefficient;

$F, \quad 1 /$ year - average failure rate;

$\Delta W, \mathrm{kWh} /$ year - average annual undersupply of electricity.

Operating time for failure of system $T_{\mathrm{H}}$ is defined as the average residence time of a process in a subset of functional states $\mathbf{X}_{\mathrm{PC}}$. For calculation of $T_{\mathbf{H}}$ following equation is used

$$
T_{\mathrm{H}}=\frac{\sum \pi_{k} a_{k}}{\sum \pi_{k} \sum p_{k l}},\left(x_{k} \in \mathbf{X}_{\mathrm{PC}}, x_{l} \in \mathbf{X}_{\mathrm{HPC}}\right),
$$

where $x_{k}$ - functional states; $x_{l}$ - non-functional states.

The average recovery time is defined as the average residence time of the process in a subset of nonfunctional states $\mathbf{X}_{\text {HPC }}$. For calculation of $T_{\mathrm{B}}$ following equation is used

$$
T_{\mathrm{B}}=\frac{\sum \pi_{l} \cdot a_{l}}{\sum \pi_{l} \sum p_{l k}},\left(x_{k} \in \mathbf{X}_{\mathrm{PC}}, x_{l} \in \mathbf{X}_{\mathrm{HPC}}\right),
$$

The system availability coefficient is defined as the stationary probability of a process being in a subset of operational states $\mathbf{X}_{\mathrm{PC}}$. For calculation of $K_{\Gamma}$ following equation is used

$K_{\Gamma}=\frac{T_{\mathrm{H}}}{T_{\mathrm{H}}+T_{\mathrm{B}}}=\frac{\sum \pi_{k} a_{k}}{\sum \pi_{k} a_{k}+\sum \pi_{l} a_{l}}$,

The average system failure rate is determined from the relation

$$
F=\frac{K_{\Gamma}}{T_{\mathrm{H}}}=\frac{\sum \pi_{k} \sum p_{k l}}{\sum \pi_{k} a_{k}+\sum \pi_{l} a_{l}},
$$


The indicators defined by formulas (3) - (6) can be differentiated according to the levels of power shortage in non-working conditions.

The average annual undersupply of electricity at the $\mathrm{i}^{\text {th }}$ level of power shortage in power supply systems is carried out based on calculated reliability indicators according to the formula

$$
\Delta W_{i}=\Delta P_{i} \cdot F_{i} \cdot T_{B i},
$$

where $\Delta P_{i}$ - power shortage level, kW; $F_{i}$-rate of failure leading to a given level of power shortage, failure/year; $T_{B i}$, hour. - average recovery time after failure with a given power shortage.

During scheduled preventive repairs (SPR) of the main elements of the system, i.e. units of power plants and system connections, the level of redundancy of the system decreases, which reduces its reliability during the specified period. The evolution of the system during SPR corresponds to its own graph of states and transitions, which allows to calculate the reliability indicators of the system in the corresponding period. The resulting reliability indicator of the system is calculated as a weighted average, taking into account the value of the corresponding indicator and the duration (hour) of the system during the year in normal and repair situations.

Reliability calculation algorithms are implemented in the RELIABILITY program, using which calculations were performed in the example below.

\section{An example of calculating the reliability indicators of the power supply system of a platform of compressor station of the marine oil production}

The compressor station of power plant consists of three units with a rated power of $2800 \mathrm{~kW}$ each. In normal mode, two units operate at a combined tire system, loaded at $50 \%$; the third unit is in reserve. In addition to the power plant units, a backup source for the compressor station is communication with the power supply system of the central platform (CPU). Communication throughput is $1600 \mathrm{~kW}$.

In case of failure of the power plant unit (intensity $\lambda_{1}$ ), it turns off and the standby unit automatically turns on. In case of unsuccessful ABP, part of the load is disconnected by the automatic unloading system. Unsuccessful ABP is characterized by probability $\boldsymbol{q}_{1}$, and successful ABP by probability $q_{3}=1-q_{1}$. After an unsuccessful ABP, the backup unit can be manually entered into operation. If there are no units in the reserve (the third unit is under repair), then if one of the two workers fails, communication with the central system is automatically turned on. The failure in automatically turn-on the communication may be due to the failure of the ABP and the non-functional state of communication at the required time.
An inoperative state of communication is determined by probability $q_{2}$, an operational state is determined by probability $q_{4}=1-q_{2}$. Communication may also fail in the course of work (intensity $\lambda_{2}$ ). During operation, system failures are possible. The intensity of these failures is $q_{5} \lambda_{3}$. The process of system recovery is determined by the intensities: $\boldsymbol{\mu}_{1}$ - recovery of units; $\mu_{2}$ - recovery of communication with the CPU; $\boldsymbol{\mu}_{3}$ - recovery after system failures; $\boldsymbol{\mu}_{4}$ - manual input into the operation of the unit; $\boldsymbol{\mu}_{5}$ - operational switching in the system.

The graph of states and transitions of the power supply system of the compressor station in the normal mode is shown in Fig. 1. The states of the system in the normal mode are shown in Table 1. Fig. 2. shows the data input interface.

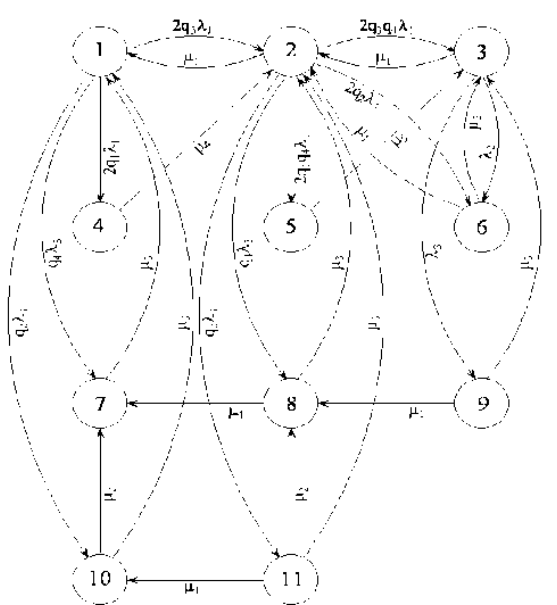

Fig. 1. Graph of state of the power supply system of the compressor station

Table 1. Identification of the state of the power supply system of the compressor station

\begin{tabular}{|c|c|c|c|c|c|c|c|}
\hline \multirow{2}{*}{$\begin{array}{c}\text { No. } \\
\text { of } \\
\text { stat } \\
\text { es }\end{array}$} & \multicolumn{4}{|c|}{$\begin{array}{l}\text { The number of units in } \\
\text { modes }\end{array}$} & \multirow{2}{*}{$\begin{array}{c}\text { Conn } \\
\text { ectio } \\
\text { n } \\
\text { with } \\
\text { CPU }\end{array}$} & \multirow{2}{*}{$\begin{array}{c}\text { Com } \\
\text { muni } \\
\text { catio } \\
\text { n } \\
\text { state }\end{array}$} & \multirow[t]{2}{*}{$\begin{array}{c}\text { Deficit, } \\
\text { kW }\end{array}$} \\
\hline & $\begin{array}{l}\text { Oper } \\
\text { ation }\end{array}$ & $\begin{array}{c}\text { Back } \\
\text { up }\end{array}$ & $\begin{array}{c}\text { Rep } \\
\text { air }\end{array}$ & $\begin{array}{c}\text { Rep } \\
\text { air } \\
\text { wait } \\
\text { ing } \\
\end{array}$ & & & \\
\hline 1 & 2 & 1 & 0 & 0 & 0 & - & 0 \\
\hline 2 & 2 & 0 & 1 & 0 & 0 & - & 0 \\
\hline 3 & 1 & 0 & 1 & 1 & 1 & 1 & 0 \\
\hline 4 & 1 & 1 & 0 & 1 & 0 & - & 400 \\
\hline 5 & 1 & 0 & 1 & 1 & 0 & 1 & 400 \\
\hline 6 & 1 & 0 & 1 & 1 & 0 & 0 & 400 \\
\hline 7 & 0 & 0 & $0, \mathrm{~S}$ & 0 & 1 & 1 & 1600 \\
\hline 8 & 0 & 0 & $1, \mathrm{~S}$ & 0 & 1 & 1 & 1600 \\
\hline 9 & 0 & 0 & $1, \mathrm{~S}$ & 1 & 1 & 1 & 1600 \\
\hline 10 & 0 & 0 & $0, \mathrm{~S}$ & 0 & 0 & 0 & 3200 \\
\hline 11 & 0 & 0 & $1, \mathrm{~S}$ & 0 & 0 & 0 & 3200 \\
\hline
\end{tabular}


Note. S - systemic fault; communication with the CPU: 1 - enabled, 0 - disabled; communication state: 1 functional, 0 - non-functional

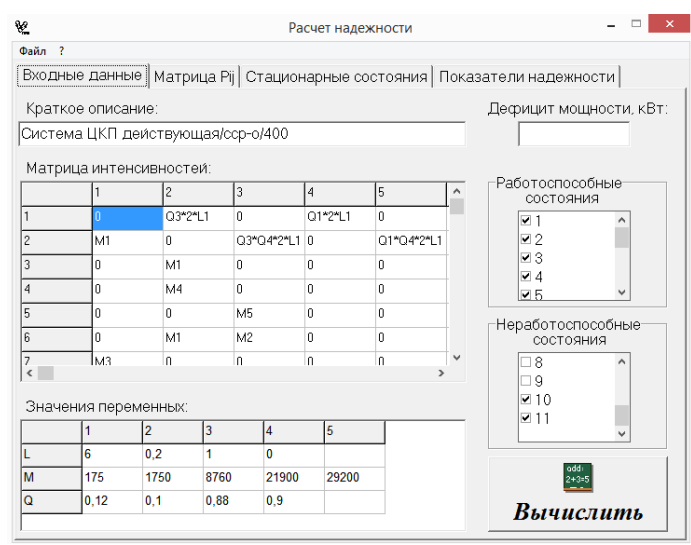

Fig. 2. Presentation form of program input data

Fig. 3. shows a fragment of the report of calculation results

Russian State University of Oil and Gas named after
I.M. Gubkin Reliability calculation program for power supply systems

Name: Compression station power supply system

Power shortage: $1400 \mathrm{~kW}$

Input data:
$\mathrm{L}(1)=6$
$\mathrm{M}(1)=175$
$\mathrm{M}(2)=1750$
$\mathrm{Q}(1)=0,12$
$\mathrm{L}(2)=0,2$
$\mathrm{M}(3)=8760$
$\mathrm{Q}(2)=0,1$
$\mathrm{L}(3)=1$
$\mathrm{M}(4)=21900$
$\mathrm{Q}(3)=0,88$
$\mathrm{M}(3)=29200$
$\mathrm{Q}(4)=0,9$

Non-functional state: 7891011

Average residence time and final state probabilities:

$\mathrm{A}[1]=0.07692$

$\Pi[1]=0.441948$

$\mathrm{A}[2]=0.00532$

$\Pi[2]=0.438208$

$\mathrm{A}[3]=0.00568$

$\Pi[3]=0.0279$

$\mathrm{A}[4]=5 \mathrm{E}-5$

$\mathrm{A}[5]=3 \mathrm{E}-5$

$\Pi[4]=0.048954$

$\mathrm{A}[6]=0.00052$

$\Pi[5]=0.003021$

$\mathrm{A}[7]=0.00011$

$\Pi[6]=0.002829$

$\mathrm{A}[8]=0.00011$

$\Pi[7]=0.031205$

$\Pi[8]=0.002139$

$\mathrm{A}[9]=0.00011 \quad \Pi[9]=0.000158$

$\mathrm{A}[10]=0.0001 \quad \Pi[10]=0.003403$

$\mathrm{A}[11]=9 \mathrm{E}-5 \quad \Pi[11]=0.000233$

Reliability indicators:

Operating time for failure $\mathrm{T}_{\mathrm{H}}=1.000128$ year

Average recovery time Тв $=0.99864$ hour

Availability coefficient $\mathrm{K}_{\Gamma}=0.999886$

Average failure rate $\mathrm{W}=0.999758$ failure/year

Expected energy deficit dW $=1397.757743 \mathrm{kWh} /$ year

Fig. 3. Fragment of listing of the output report of the program

\section{Conclusion}

A method for calculating the reliability of power supply systems with autonomous power supplies is proposed, which is developed based on analysis of the features of power supply for oil and gas industry objects and allowing more reasonably choosing options for power supply of industrial complexes during their design and reconstruction. The technology was created on the basis of semi-Markov random processes, brought to a software implementation and is effective for rapid assessment of the reliability of systems with autonomous power sources.

\section{References}

1. Menshov B.G., Ershov M.S. Reliability of power supply systems of compressor stations. - M.: Nedra, 1995.

2. Ershov M.S., Zyong Hoang Hai. The methodology for calculating the reliability of SES complexes of stationary marine oil production platforms // Automation, telemechanization and communication in the oil industry, 2006, No. 9, p. 35-38.

3. Reliability of energy systems and their equipment. Reference: in 4 vol. Vol. 2. Reliability of electric power systems / Ed. M.N. Rudenko. - M .: Energoatomizdat, 2000.

4. Sukharev M.G., Ershov M.S. The reliability model of a duplicated system with limitations of the backup element // Reliability and quality control, 1985, No. 3, p. $18-22$

5. Reliability of technical systems. Handbook / Ed. I.A. Ushakov. - M .: Radio and communications, 1985.

6. Polovko A.M., Gurov S.V. Fundamentals of reliability theory. $-2^{\text {nd }}$ ed., reviewed and added $-\mathrm{SPb}$.: BHV-Petersburg, 2006.

7. Credentser B.P. Prediction of the reliability of systems with temporary redundancy. - Kiev: Naukova dumka, 1988.

8. Billinton R., Allan R., Reliability evaluation of power systems, N.Y.: Plenum Press, 1987.

9. P. Wang, R. Billinton, "Reliability cost/worth assessment of distribution systems incorporating timevarying weather conditions and restoration resources", IEEE Trans on Power Delivery, vol. 17, no. 1, 2002, pp. 260-265.

10. Jalilov R.B. Structural redundancy to increase the reliability of power supply to consumers. // Electrics, 2007, No.6, p. 27-29.

11. Jalilov RB, Sitdikov R.A. Graph-analytical method for studying the reliability of electric power systems. // Problems of energy and resource saving, Tashkent, 2017. No.1-2, pp. 23-29. 